\title{
Mittelwerte - zwischen Wahrheit und Lüge \\ Oder: \\ Wie sich aus einem mathematischen Lehrsatz \\ Kapital für die Werbung schlagen lässt
}

\section{von Alfred Schreiber}

Die Mathematik hat wichtige Anwendungen in Naturwissenschaften, Technik und Ökonomie. Für den Alltag nutzt Otto Normalverbraucher allerdings meist nur die Grundrechenarten und ein wenig Dreisatz. Bisweilen kommt man damit aber schon weit sogar über vordergründig Praktisches hinaus zum kritischen Verständnis eines Sachverhalts, einer Situation. Auch das eine nützliche Seite der Mathematik.

Ein Beispiel liefern Mittelwerte. Selten wird im täglichen Leben genau gefragt, welche Art von Durchschnitt zu ermitteln ist und vor allem: mit welcher sachlichen Begründung. Meistens berechnet (und kennt) man nur das arithmetische Mittel $(M)$. Kostet eine Ware in drei aufeinanderfolgenden Monaten 50 Euro, 70 Euro und 63 Euro, so ist ihr mittlerer Preis $M=\frac{50+70+63}{3}=61$ Euro. Ähnlich verfährt man mit Gewichten, Temperaturen, Körpergrößen, Einkommen ... Aber Vorsicht! Wieviel Wahrheit liegt in der Angabe eines Durchschnittseinkommens von 3800 Euro, wenn von zehn befragten Personen eine 20000 Euro verdient und die übrigen nur ein Zehntel davon? Oder nehmen wir den vielbeschworenen Durchschnittsbürger. Könnte man ihn etwa mit Schuhen vom arithmetischen Größenmittel aller Schuhgrößen versorgen? - Nicht unumstritten ist die verbreitete Praxis, Zeugnisnoten arithmetisch zu mitteln. Verhalten sich etwa die Noten sehr gut bis ungenügend tatsächlich so wie 1 bis 6 auf dem Zahlenstrahl? Das wird nicht jedem einleuchten.

Kehren wir noch einmal zum ersten Beispiel zurück und nehmen an, die Preise 50, 70, 63 beziehen sich auf 1 Anteil eines Wertpapierfonds. Das Besondere an der Fondsanlage: Man kann mit gleichbleibenden Einzahlungen auch gebrochene Anteile erwerben. Für 150 Euro monatlich wären dies 150/50 (=3), 150/70 (= $2,143)$ und $150 / 63(=2,381)$ Anteile. Da die insgesamt 7,524 Anteilbruchteile $3 \times 150$ Euro kosten, macht dies für 1 Anteil 450/7,524= 59,81 Euro. Dieser Durchschnittseinstandspreis ist um 1,19 Euro niedriger als der Durchschnittsausgabepreis von 61 Euro. Ist das Zufall? Oder verdanken wir diesen sogenannten CostAverage-Effekt dem geschickten Anlagemanagement erfahrener Börsenprofis, wie uns manchmal die Werbung glauben machen möchte?

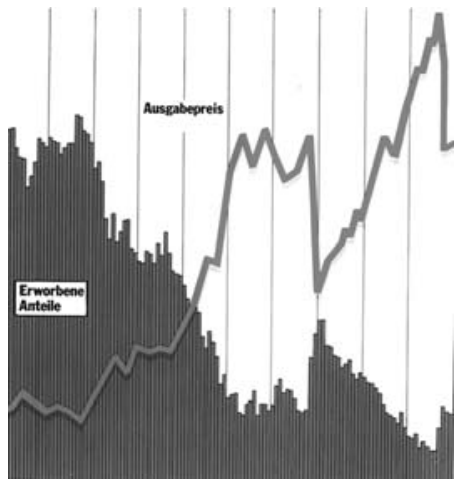

Zeigt ein Kursverlauf wie dieser, dass man mit regelmäßigen Einzahlungen ,über einen langen Zeitraum hinweg" vom Cost-Average profitiert? Interessanterweise ist die Wahrheit hier einmal rein mathematisch. Schauen wir genauer hin: Der Durchschnittseinstandspreis, so wie eben berechnet, wird durch den Doppelbruch

$$
\frac{3 \times 150}{\frac{150}{50}+\frac{150}{70}+\frac{150}{63}}=\frac{3}{\frac{1}{50}+\frac{1}{70}+\frac{1}{63}} \approx 59,81
$$

dargestellt - das seit alters her bekannte harmonische Mittel $H$ (hier: der Zahlen 50, 70, 63). Bekanntlich ist $H$ stets kleiner als $M$ ist, wenn die beteiligten Zahlen nicht alle gleich sind. Im Beispiel der Fondsanlage heißt niedriger Kurs automatisch mehr billige Anteile, höherer Kurs weniger teure Anteile - ganz unabhängig von Erfahrung oder Können. Ob man dabei Gewinn macht, hängt am Ende vom Kursunterschied bei Kauf und Verkauf ab. Wer für die 450 Euro im ersten Monat 9 Anteile kauft und einen Monat später wieder verkauft, hat's richtig gemacht.

\section{Adresse des Autors}

Prof. Dr. Alfred Schreiber

Institut für Mathematik und ihre Didaktik

Universität Flensburg

Auf dem Campus 1

24943 Flensburg

schreiber@uni-flensburg.de 